\title{
Modelling pesticide runoff from paddocks in the Great Barrier Reef using HowLeaky
}

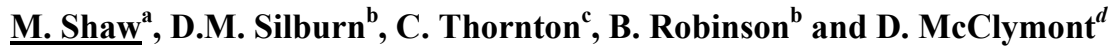 \\ ${ }^{a}$ Land Resource Assessment, Environment and Resource Sciences, Queensland Department of \\ Environment and Resource Sciences \\ ${ }^{b}$ Planning and Assessment, South West Region, Queensland Department of Environment and Resource \\ Sciences \\ ${ }^{c}$ Biloela Research Station, Central West Region, Queensland Department of Environment and Resource \\ Sciences \\ ${ }^{d}$ DHM Environmental Software Engineering Pty. Ltd. \\ Email: melanie.shaw@derm.qld.gov.au
}

\begin{abstract}
Herbicides applied in cropping in the Great Barrier Reef catchment in Queensland, pose a threat to water quality in riverine environments and the reef lagoon. With the introduction of ReefPlan in 2009, which sets a target of a 50\% reduction in herbicides entering the Great Barrier Reef lagoon by 2013, there is a need to investigate water quality implications of weed management practices. Models are the most logical approach to extrapolate from the relatively small experimental database to a wider range of conditions and also investigate the impact of management options. Towards this end, a pesticide module has been added to the HowLeaky crop and soil water balance model. This pesticide module is based on algorithms from GLEAMS. An extraction coefficient to predict concentrations of chemicals in runoff as a function of soil concentrations is a central concept. Good agreement has been found between model predictions and measured data for pesticide runoff from experimental field sites. Sensitivity analysis shows major factors affecting transport potential are the application rate and degradation rate of the pesticide. Using modelled simulations, the water quality impacts of weed management practices incorporating a heavy reliance on residual herbicides (atrazine, diuron) in grains farming have been explored and compared to the use of knockdowns herbicides (e.g. 2,4-D, glyphosate). Several pesticides that are being increasingly used in the grains and cane industry in Queensland are also assessed (e.g. isoxaflutole, s-metolachlor, pendimethalin). Simulation results demonstrate that reducing the use of residuals in favour of knockdown herbicides would result in an improvement in runoff water quality. However, caution is needed when selecting 'emerging' pesticides to replace the traditionally applied residuals, as use of these products may not lead to improved water quality. The examples presented demonstrate the utility of the HowLeaky
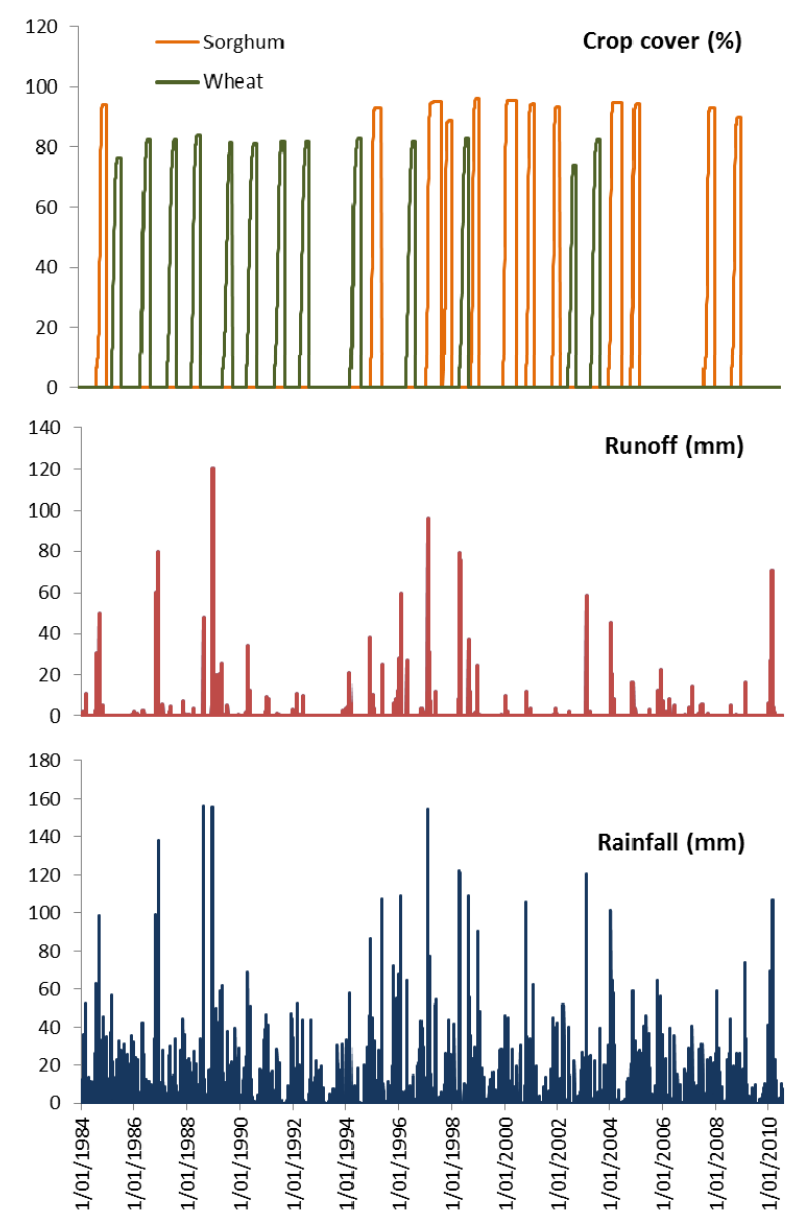
pesticides module for exploring runoff water quality implications from weed management practice options in cropping lands.

Figure A1. Crop rotations, runoff and rainfall events simulated with HowLeaky for the Brigalow Catchment Study.

Keywords: Herbicide, runoff, residual, knockdown, sensitivity analysis 


\section{INTRODUCTION}

Pollutants in runoff from agricultural land pose a threat to downstream aquatic ecosystems. In Australia, broadacre cropping in the catchment area of the World Heritage Listed Great Barrier Reef (GBR) has been linked to elevated loads of sediments, nutrients and pesticides entering the GBR lagoon (Lewis et al., 2009, Packett et al., 2009). Reef Plan (2009) sets a target of a 50\% reduction in the loads of nutrients and herbicides by 2013 and a $20 \%$ reduction in sediments by 2020 . More specifically, the plan calls for a reduction in the loads of herbicides that inhibit functioning of photosynthesis at photosystem II in plants (PSII herbicides).

An initiative designed to support Reef Plan provides incentives to landholders to adopt improved management practices designed to lead to improved water quality. Conservation/zero tillage farming is encouraged as a practice that will increase ground cover and thereby reduce runoff and soil erosion. However, in the absence of cultivation, herbicides are an important tool in effective weed control.

Under best management practice guidelines (e.g. NQ DryTropics, 2009), reduced reliance on the use of 'residual' herbicides in favour of 'knockdown' herbicides is considered an improved farming practice. Residual herbicides are applied pre-emergence to prevent seeds germinating and/or emerging, and as such are required to persist for a period of time after application. Knockdown herbicides are used to kill emerged weeds and therefore generally have shorter half-lives than residual herbicides. Commonly applied residual herbicides are the PSII inhibiting compounds which are frequently detected in GBR waterways and in the GBR lagoon; atrazine, diuron, ametryn and hexazinone (Lewis et al., 2009, Shaw et al., 2010). The focus on reducing the use of these PSII herbicides has anecdotally led to increasing use of alternative residual herbicides, from here on referred to as 'emerging' herbicides. While this may be a positive outcome for water quality entering the Great Barrier Reef, it is an issue that requires further investigation.

Simulation models provide the opportunity to extend currently available observed data to investigate potential environmental impacts of land management scenarios. HowLeaky is a one dimensional model which simulates a soil water balance under crop growth and land management conditions at the paddock scale (Robinson et al., 2010). A pesticide module has been incorporated in HowLeaky which tracks dissipation of pesticides in the soil, crop stubble and vegetation and estimates pesticide concentrations in runoff partitioned between soluble and sediment bound phases (enhanced from Rattray et al., 2004). The predictive ability of this pesticides model, which is based on relatively simple assumptions and empirical evidence, requires testing against experimental data. Input parameters in many cases have to be derived from datasets generated for temperate regions or estimated, and have different levels of uncertainty. Therefore, it also becomes critical to know those parameters to which the final model output is most sensitive.

In this paper, we examine the predictive ability of the HowLeaky pesticide module against an experimental dataset from a cropped catchment in Queensland. A sensitivity analysis is conducted to determine the parameters of greatest importance in predicting pesticide soil concentrations and the loss in runoff, and the model is used to explore the relative water quality benefits of an increased reliance on knockdown or emerging herbicide products for weed control.

\section{METHODS}

\subsection{Model Description}

The HowLeaky water balance and crop growth models are based on PERFECT (Littleboy et al., 1992) and have been described elsewhere (Robinson et al., 2010). Equations implemented in the pesticides module have been adapted from CREAMS/GLEAMS (Leonard et al., 1987) and have been described by Rattray et al. (2004) with new processes added for pesticides on the crop canopy and residue pools. Adaptations to the model have been based on experimental work conducted in Australia (Silburn, 2003). Algorithms implemented to describe major transport processes and pathways are shown in Table 1. HowLeaky Version 5.35 .03 beta has been used in the current study.

\subsection{Experimental runoff data}

HowLeaky model scenarios were constructed to simulate an experimental data set from a cropping study site in the Fitzroy River Basin of Central Queensland; the Brigalow Catchment Study (Cowie et al., 2007). Selected soil properties of the Black Vertosol at this site are presented in Table 2. Surface soil $(25 \mathrm{~mm}$ ) has a measured $\mathrm{pH}$ of 6.86 , organic carbon content of $1.08 \%$ and a clay fraction of $35 \%$. The site experiences a semi-arid to subtropical climate with a summer-dominated rainfall pattern. 
Table 1. Pesticide module components in HowLeaky

\begin{tabular}{|c|c|c|}
\hline Model component & Equation & Comments \\
\hline Pesticide application & $\begin{array}{c}M_{0 \text { Crop }}=P_{C} \cdot P_{R} \cdot P_{E} \cdot S_{B} \cdot C_{C r o p} \\
M_{0 \text { Stubble }}=P_{C} \cdot P_{R} \cdot P_{E} \cdot S_{B} \cdot C_{\text {Stubble }} \\
M_{0 \text { Soil }}=P_{C} \cdot P_{R} \cdot P_{E} \cdot S_{B}-\left(M_{0 \text { Crop }}+M_{0 \text { Stubble }}\right.\end{array}$ & $\begin{array}{l}\text { The mass of pesticide applied is calculated as a } \\
\text { function of product concentration }\left(\mathrm{P}_{C}\right) \text {, product rate } \\
\left(\mathrm{P}_{\mathrm{R}}\right) \text {, product efficiency }\left(\mathrm{P}_{\mathrm{E}}\right) \text { and banding rate }\left(\mathrm{S}_{\mathrm{B}}\right) \text {. } \\
\text { Applied pesticides are distributed between crop, } \\
\text { stubble and the soil surface based on \% cover }(\mathrm{C}) \text {. }\end{array}$ \\
\hline $\begin{array}{l}\text { Wash off from } \\
\text { crop/stubble to soil }\end{array}$ & Washoff $=M_{t} \cdot f_{C W}$ & $\begin{array}{l}\text { Wash off may occur once after an application and is } \\
\text { triggered by } 5 \mathrm{~mm} / \text { day rainfall. The amount washed } \\
\text { off is determined by the wash off coefficient }\left(\mathrm{f}_{\mathrm{CW}}\right) \\
\text { and is added to the soil residues. }\end{array}$ \\
\hline $\begin{array}{l}\text { Temperature dependant } \\
\text { half life }\end{array}$ & $t_{1 / 2}=t_{1 / 2 \operatorname{Exp}} e^{\frac{E_{a}}{R} \cdot\left(\frac{1}{T_{t}}-\frac{1}{T_{E x p}}\right)}$ & $\begin{array}{l}\text { The half-life }\left(t_{1 / 2}\right) \text { is re-calculated daily based on the } \\
\text { average air temperature }(T) \text { and a reference half-life } \\
\left(\mathrm{t}_{1 / 2 \text { Exp }}\right) \text { at a known temp }\left(\mathrm{T}_{\text {Exp }}\right) \text { assuming an } \\
\text { Arrhenius relationship (Walker et al., 1997). }\end{array}$ \\
\hline Degradation & $M_{t}=M_{0} e^{k t}$ & $\begin{array}{l}\text { Pesticide mass }\left(\mathrm{M}_{\mathrm{t}}\right) \text { is calculated daily }(\mathrm{t}) \text { for each } \\
\text { compartment assuming a first order degradation rate } \\
\text { constant }(\mathrm{k}) \text {, where } \mathrm{t}_{1 / 2}=\ln _{\mathrm{e}}(2) / \mathrm{k} \text {. }\end{array}$ \\
\hline $\begin{array}{l}\text { Soil concentration after } \\
\text { leaching }\end{array}$ & $C_{a v}=C_{S o i l} e^{\left(-\frac{\text { inf iltration }}{M L(K d . B D+\text { porosity })}\right)}$ & $\begin{array}{l}\text { Soil concentration available for loss in runoff }\left(\mathrm{C}_{\mathrm{av}}\right) \text { is } \\
\text { calculated after leaching losses. Leaching is a } \\
\text { function of infiltration, mixing layer depth }(\mathrm{ML}) \text {, } \\
\text { partition coefficient (Kd), bulk density (BD) and } \\
\text { porosity. }\end{array}$ \\
\hline $\begin{array}{l}\text { Concentration in soluble } \\
\text { and sorbed runoff }\end{array}$ & $\begin{array}{l}C_{\text {Water }}=\frac{C_{a v} \beta}{1+K d \cdot \beta} \\
C_{\text {Sed }}=\frac{C_{a v} K d \cdot \beta}{1+K d \cdot \beta}\end{array}$ & $\begin{array}{l}\text { An extraction coefficient (B) is used to calculate the } \\
\text { fraction of pesticide lost in runoff. This concept is } \\
\text { based on empirical evidence that the fraction } \\
\text { extracted is constant regardless of pesticide } \\
\text { properties (Silburn, 2003). A partition coefficient } \\
(\mathrm{Kd}) \text { is used to determine the fraction of pesticide in } \\
\text { soluble runoff }\left(\mathrm{C}_{\mathrm{W}_{\text {ater }}}\right) \text { vs sorbed runoff }\left(\mathrm{C}_{\mathrm{Sed}}\right) \text {. }\end{array}$ \\
\hline Total loss in runoff & Load $=C_{\text {Water }} \cdot R+C_{\text {Sed }} \cdot E$ & $\begin{array}{l}\text { The total mass of pesticide lost in runoff is } \\
\text { calculated as } C_{\text {water }} \text { by the runoff volume }(\mathrm{R}) \text { and } \mathrm{C}_{\mathrm{Sed}} \\
\text { by the sediment lost }(\mathrm{E}) \text {. }\end{array}$ \\
\hline
\end{tabular}

Rainfall averages $697 \mathrm{~mm} / \mathrm{yr}(246-1460 \mathrm{~mm})$ while evaporation averages $2100 \mathrm{~mm} /$ year. Wheat and sorghum have been planted on an opportunistic basis since 1995, whenever soil water and planting rains permitted. Fallows have been maintained by reduced-tillage and later zero-tillage. Herbicides have been applied since 1989 and products used include atrazine, fluroxypyr, glyphosate and 2,4-D.

Table 2. Modelled soil parameters for the Brigalow Catchment Study.

\begin{tabular}{llllll}
\hline & Layer1 & Layer2 & Layer3 & Layer4 & Layer5 \\
\cline { 2 - 5 } Bottom of layer (mm) & 100 & 400 & 800 & 1200 & 2000 \\
Wilting Point (\%) & 16 & 16 & 22 & 25 & 29 \\
Field Capacity (\%) & 34 & 37 & 35 & 33 & 35 \\
Saturation (\%) & 54 & 40 & 37 & 37 & 39 \\
Bulk density $\left(\mathrm{g} \mathrm{cm}^{-3}\right)$ & 1.23 & 1.58 & 1.6 & 1.7 & 1.6 \\
\hline
\end{tabular}

Runoff volumes and water quality samples have been collected from the site using a $1.2 \mathrm{~m}$ HL flume fitted with a stage height recorder. Water quality has been monitored using discreet grab samples collected across the hydrograph as rising stage samples. Since 2000, these samples have been collected by an automated sampler. Runoff water has been analysed for each of the pesticide active ingredients for runoff events from 2002. For the purpose of this study we simulated the crop rotations from 1984 to 2010 and calibrated the model by minimizing the differences between measured and predicted surface water runoff and surface cover estimates.

\subsection{Sensitivity analysis}

Runoff loads of pesticides at the edge of a field and residual mass in the soil mixing layer (top 25mm) were compared to determine sensitivities of input parameters. The sensitivity index $\left(\mathrm{S}_{i}\right)$ for a parameter or variable has been defined after Ma et al. (2004) as:

$S_{i}=\left(\frac{P_{i}-P_{i}^{b}}{P_{i}^{b}}\right) .100$

where $P_{i}$ is the prediction with varying parameter $\mathrm{i}$ and $P_{i}^{b}$ is the same prediction with the corresponding base value. It should be noted that the magnitude $\mathrm{S}_{i}$ is not influenced by the units of the parameters. Inputs for the analysis are given in Table 3. 


\subsection{Herbicide product comparison}

Using the Brigalow Catchment study model scenarios, a comparison was made of the potential offsite losses of a range of herbicide products; PSII residuals (atrazine and diuron), knockdowns (2,4-D and glyphosate) and emerging herbicides (s-metolachlor, isoxaflutole and pendimethalin). Pesticide properties used to simulate the total loss of pesticides from a paddock are shown in Table 3.

A simulation was constructed with applications of each product tank mixed at label rates, to compare the impact of physical properties on runoff losses (recognising that these products are not all registered for use on wheat or sorghum). Applications were not banded for any of the products and the application efficiency was assumed to be $100 \%$. Simulation of a weed management strategy focusing on knockdowns and substituting s-metolachlor for heavy reliance on the PSII residual atrazine was also investigated.

Table 3. Selected properties of tested herbicides.

\begin{tabular}{|c|c|c|c|c|c|c|c|}
\hline & \multicolumn{2}{|c|}{ Residuals } & \multicolumn{2}{|c|}{ Knockdowns } & \multicolumn{3}{|c|}{ Emerging } \\
\hline & Atrazine & Diuron & $2,4-\mathrm{D}$ & Glyphosate & $\begin{array}{c}\text { Isoxaflutole } \\
\text { (Balance) }\end{array}$ & $\begin{array}{l}\text { Pendimethalin } \\
\text { (Stomp) }\end{array}$ & $\begin{array}{l}\text { S Metolachlor } \\
\text { (Dual Gold) }\end{array}$ \\
\hline 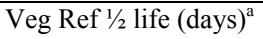 & 14.5 & 30 & 5 & 6 & 0.65 & 30 & 10.5 \\
\hline Soil Ref $1 / 2$ life (days) ${ }^{a}$ & 29 & 89 & 10 & 12 & 1.3 & 90 & 21 \\
\hline $\operatorname{DAE}\left(\mathrm{J} \mathrm{mol}^{-1}\right)^{\mathrm{b}}$ & 54900 & 20400 & 65400 & 65400 & 65400 & 90900 & 65400 \\
\hline Sorption coeff ${ }^{\mathrm{a}}$ & 1 & 12 & 0.6 & 234 & 1.2 & 170 & 2.2 \\
\hline Wash off coeff & 0.45 & 0.45 & 0.45 & 0.6 & $0.5^{*}$ & 0.4 & 0.6 \\
\hline Extraction coeff ${ }^{\mathrm{d}}$ & 0.2 & 0.2 & 0.2 & 0.2 & 0.2 & 0.2 & 0.2 \\
\hline Rate $(\mathrm{L} \text { or } \mathrm{Kg} / \mathrm{ha})^{\mathrm{e}}$ & 2 & 1.1 & 1.7 & 2 & 0.1 & 2.2 & 1.5 \\
\hline
\end{tabular}

${ }^{\text {a }}$ Pesticides properties database (Footprint, PPDB), vegetation half-life derived from the soil half-life using rules from SWAT.

${ }^{\mathrm{b}}$ Degradation Activation Energy, values from Walker et al., (1997), EFSA (2007), or default of 65400J $\mathrm{mol}^{-1}$ if no compound specific estimates available.

${ }^{\mathrm{c}}$ SWAT pesticides properties database. *Estimated from relationship between solubility and available wash off coefficients.

${ }^{\mathrm{d}}$ Silburn (2003).

${ }^{\mathrm{e}}$ Label rates for grains crops, i.e. wheat, sorghum or chickpeas.

\section{RESULTS AND DISCUSSION}

\subsection{Predicting runoff and herbicide loss for an experimental site}

Simulated crop rotations and rainfall and runoff events are presented in the Appendix (Figure A1). Modelled soil concentrations of atrazine and the predicted and measured runoff concentrations are shown in Figure 1. Following some adjustment of parameters to fit measured data, there was good agreement between predicted and measured daily runoff $(\mathrm{mm})$ $\left(\mathrm{R}^{2}=0.76\right)$. Predicted runoff concentrations and loads for all events with a measured herbicide concentration (including atrazine, glyphosate, fluroxypyr and 2,4-D) were well correlated with the measured data $\left(\mathrm{R}^{2}=0.8, \mathrm{R}^{2}=0.92\right.$ respectively). Inspection of Figure 1 shows that while most events with a measured value were well predicted, there were two events where the measured values were more than two times greater than the predicted values. Predicted runoff on these days was also double the

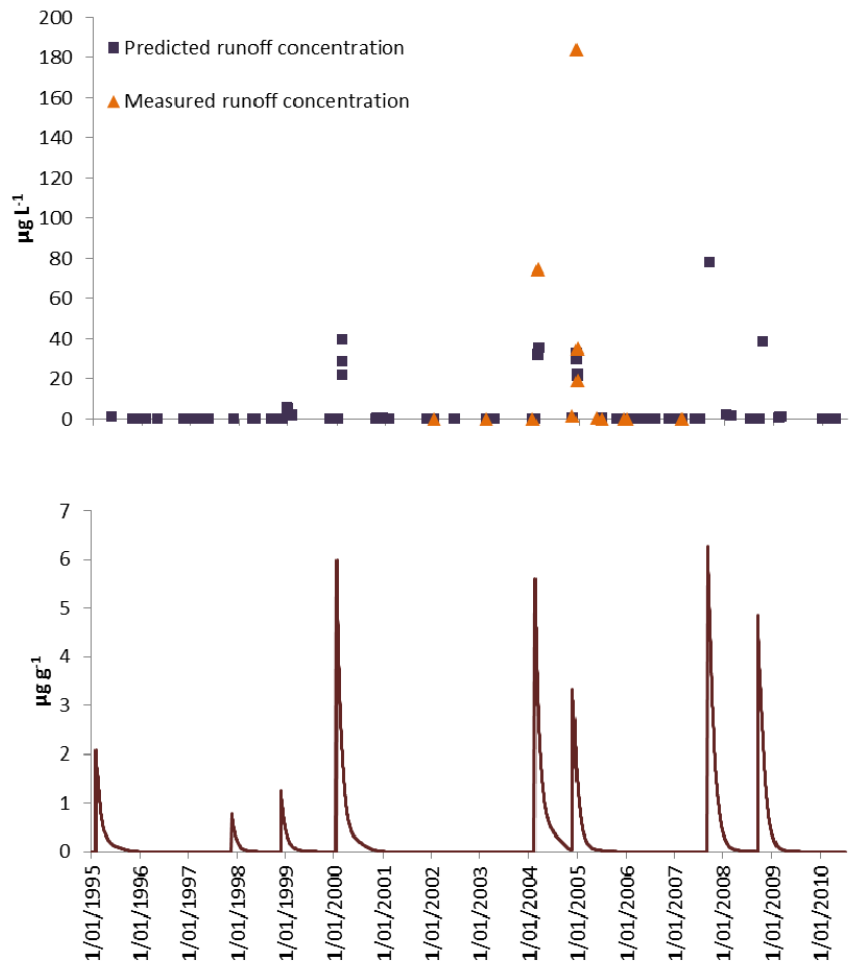

Figure 1. Measured versus predicted atrazine runoff $\left(\mu \mathrm{g} \mathrm{\textrm {L } ^ { - }}\right.$ $\left.{ }^{1}\right)$ from the Brigalow Catchment Study above and modelled soil concentration for atrazine below. Measurements began in 2002 . 
measured runoff, indicating that the pesticide mass transported was diluted in the simulation. While runoff was generally well predicted, on a particular day it may not be predicted accurately. Overall, HowLeaky appeared to provide a good representation of the measured data from the Brigalow Catchment Study.

\subsection{Sensitivity analysis}

The results of the sensitivity of predicted soil surface concentrations and the total loss in runoff (loads) for the herbicide atrazine are summarised in Table 4. Similar results were observed for other herbicides investigated. Parameters that resulted in a greater than $20 \%$ variance in the model output when the value was varied by $25 \%$ are marked in bold. As was expected, the half-life of the herbicide had the greatest influence on the loss of atrazine in runoff. This highlights the importance of experimental data to derive locally relevant half-life values on Australian soils in tropical climates. Half-life on the crop and stubble had only a minimal influence on the model outputs. Wash off from the crop and stubble to the soil only occurs once after an application event and only on a day with $>5 \mathrm{~mm}$ rainfall. Further, extraction of pesticides into runoff only occurs from the soil and pesticides do not move from the stubble directly into runoff. These assumptions require further investigation, but explain the low sensitivity of the model to half-life on the crop and stubble.

The total loss in runoff was moderately sensitive to the extraction coefficient, and less sensitive to the sorption coefficient. The extraction coefficient in this model is used to determine the total fraction of available pesticide in the soil that is transported by runoff and then the partition coefficient defines the fraction of this total that is sorbed to sediment. Soil concentration estimates were not sensitive to either of these parameters. The relatively high sensitivities of pesticide application parameters, banded spray $\%$ and application efficiency $\%$, for predictions of atrazine soil surface concentrations and loss in runoff suggest that accurate predictions of pesticide fate depend on information on how they are applied as well as physical chemical properties. These factors are important in calculation of the starting pesticide soil concentrations. However, other factors that also directly affect the calculation of soil concentration, bulk density and mixing layer thickness, impacted soil concentrations to a greater extent than loss in runoff.

Table 4. Sensitivity analysis parameters and results for atrazine. $S_{i}($ Eqn 1$)-\%$ change in response.

\begin{tabular}{|c|c|c|c|c|}
\hline Parameter & $\begin{array}{c}\text { Base } \\
\text { value }\end{array}$ & $\begin{array}{c}\text { Variation (\% of } \\
\text { base value) }\end{array}$ & $\begin{array}{l}S_{\mathrm{i}} \text {-Soil surface } \\
\text { concentration }\end{array}$ & $\begin{array}{c}S_{i}-\text { Total loss } \\
\text { in runoff }\end{array}$ \\
\hline \multicolumn{5}{|l|}{ PhysChem properties } \\
\hline \multirow[t]{2}{*}{ Half-life (soil) } & 29 & +25 & 22 & 119 \\
\hline & & -25 & -22 & -72 \\
\hline \multirow[t]{2}{*}{ Half-life (vegetation) } & 14.5 & +25 & 1.9 & 5.1 \\
\hline & & -25 & -2.3 & -5.5 \\
\hline \multirow[t]{2}{*}{ DAE } & 54900 & +25 & 8.8 & 3 \\
\hline & & -25 & -9.2 & -5 \\
\hline \multirow[t]{2}{*}{ Sorption coefficient $(\mathrm{Kd})$} & 1 & +25 & 0.1 & 19 \\
\hline & & -25 & -0.1 & -21 \\
\hline \multirow{2}{*}{ Extraction coefficient } & 0.2 & +25 & -0.005 & 24 \\
\hline & & -25 & 0.005 & -24 \\
\hline \multirow[t]{2}{*}{ Foliar wash off fraction } & 0.45 & +25 & -0.12 & -0.19 \\
\hline & & -25 & -1.9 & -3.3 \\
\hline \multicolumn{5}{|l|}{ Application parameters } \\
\hline \multirow[t]{2}{*}{ Banded spray (\%) } & 50 & +25 & 25 & 25 \\
\hline & & -25 & -25 & -25 \\
\hline \multirow[t]{2}{*}{ Application efficiency } & 50 & +25 & 25 & 25 \\
\hline & & -25 & -25 & -25 \\
\hline \multicolumn{5}{|l|}{ Other } \\
\hline \multirow[t]{2}{*}{ Mixing layer thickness } & 25 & +25 & -19 & 1.9 \\
\hline & & -25 & 39 & -12 \\
\hline \multirow{2}{*}{ Soil bulk density } & 1.3 & +25 & -21 & -11 \\
\hline & & -25 & 30 & 14 \\
\hline
\end{tabular}

\subsection{Herbicide product comparison}

Figure 2 shows average daily runoff concentrations $\left(\mu \mathrm{g} \mathrm{L}^{-1}\right)$ for the residual, knockdown and emerging herbicides across the 26 year simulation period. In this scenario, all pesticides were applied on the same days at label rates. While this is unrealistic, the scenario allows for a comparison of the influence of the physical chemical properties of a product on transport in runoff. Concentrations in runoff of the knockdown products were notably lower than for the residual herbicides. The average daily 2,4-D concentrations were more than 100 times lower than for diuron. Similarly, runoff concentrations of the emerging herbicide isoxaflutole were more than 500 times lower than for diuron and atrazine. 
Applications of s-metolachlor and pendimethalin resulted in average runoff concentrations higher than observed for atrazine, but still lower than for diuron. S-metolachlor and pendimethalin are both relatively toxic to aquatic plants and other aquatic organisms, although they are not PSII inhibitors. These predictions are consistent with the sensitivity of the model to soil half-life values, as both smetolachlor and pendimethalin have longer reported half-lives than atrazine. An important factor in accurately simulating the fate of these and other emerging herbicides will be availability of fate data for these less studied compounds.

In a more realistic scenario, with herbicides applied as per common practice in central Queensland grains cropping (Strahan et al., 2009), the shift from heavy reliance on atrazine to knockdowns and the use of s-metolachlor was simulated. The load of atrazine transported off the field over the 26 year simulation was reduced more than four times under the improved management; however, the total loss of s-metolachlor for this scenario was similar to that for atrazine. Therefore, there was an overall reduction of approximately $50 \%$ of the offsite transport of residual herbicides. Offsite transport of knockdown products did not increase under the simulations which included improved tillage practices.

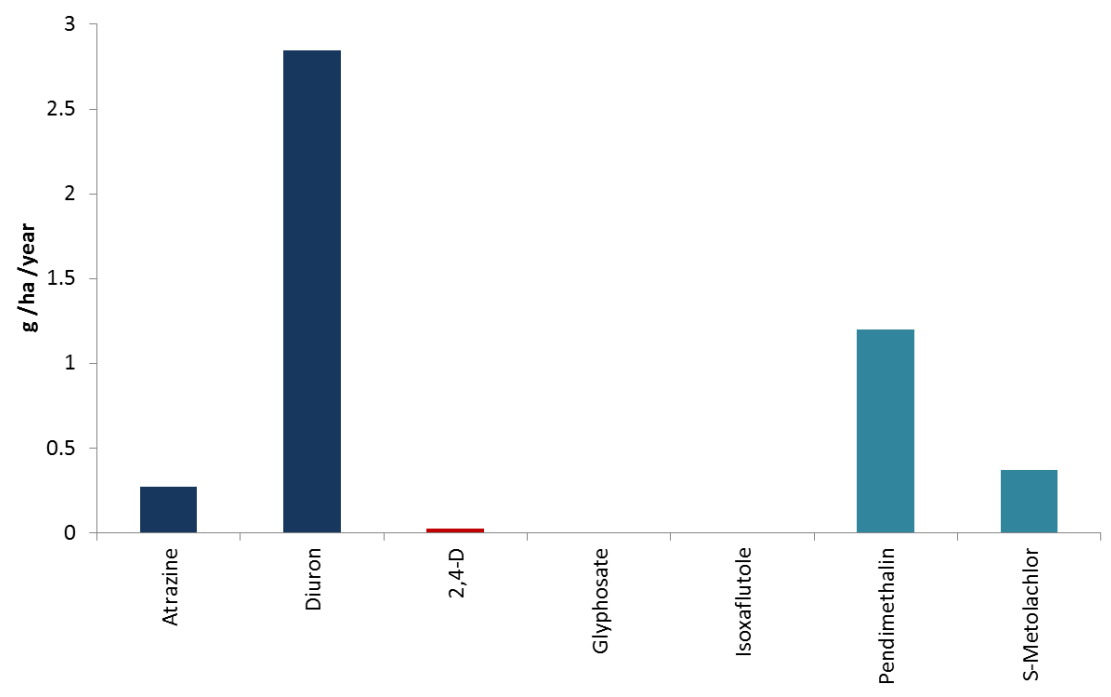

Figure 2. Simulated mean annual runoff loads for 2 residual (dark blue), 2 knockdown (red) and 3 'emerging' herbicide products (light blue).

Here we have considered the offsite transport potential under straightforward application scenarios, a complete assessment of the benefits of increased use of knockdown herbicides over residuals would need to account for the potential for more frequent applications to be required and the environmental costs associated with responding to rather than preventing weed growth. In addition to product substitutions, management options for reducing pesticide loss in runoff, including reduced application rates, banded applications and timing applications relative to rainfall events have not been explored here but should be considered in future model scenarios.

\section{CONCLUSIONS}

The HowLeaky pesticide model predicted herbicide loss in runoff reasonably well at a site where an extensive experimentally derived parameter set was available. Predicted losses in runoff were most sensitive to the input of a reference half-life, which highlights the importance of locally derived dissipation data for tropical regions and Australian soils. Inputs for application rates and methods were also found to be important model parameters for predicting loss in runoff.

Simulation of a shift away from reliance on residual herbicides towards greater usage of knockdown products indicates that these practices will lead to an improvement in runoff water quality. This is particularly true when the lower toxicity of the knockdown products is taken into account (ANZECC/ARMCANZ, 2000). However, it is clear that there is a need for further investigation into the water quality implications of increasing usage of alternative residual herbicides such as smetolachlor and pendimethalin. A shift to these products over the traditional residual products such as atrazine and diuron will not necessarily be better for the health and resilience of downstream ecosystems. The current study represents a simplistic investigation of this issue; however, it demonstrates the utility of the HowLeaky simulation model. 


\section{REFERENCES}

Anon. (2009). The State of Queensland and Commonwealth of Australia. Reef water quality protection plan; for catchments adjacent to the Great Barrier Reef World Heritage Area. Queensland Department of Premier and Cabinet, Brisbane, http://www.reefplan.qld.gov.au/.

ANZECC and ARMCANZ. (2000). Australian and New Zealand guidelines for fresh and marine water quality. Volume 1 - the guidelines. National water quality management strategy paper No 4. Australian and New Zealand Environment and Conservation Council and Agriculture and Resource Management Council of Australia and New Zealand, Canberra, Australia.

Cowie, B.A., Thornton, C.M. and Radford, B.J. (2007). The Brigalow Catchment Study: I. Overview of a 40-year study of the effects of land clearing in the brigalow bioregion of Australia. Australian Journal of Soil Research 45, 479-495.

EFSA (2007). Opinion on a request from EFSA related to the default $Q 10$ value used to describe the temperature effect on transformation rates of pesticides in soil. The EFSA Journal 622, 1-3.

Leonard, R.A., Knisel, W.G. and Still, D.A. (1987). GLEAMS: groundwater loading effects of agricultural management systems. Transactions of the ASAE 30, 1403-1418.

Lewis, S., Brodie, J., Bainbridge, Z., Rohde, K., Davis, A., Masters, B., Maughan, M., Devlin, M., Mueller, J. and Schaffelke, B. (2009). Herbicides: a new threat to the Great Barrier Reef. Environmental Pollution 157, 2470-2484.

Ma, Q., Wauchope, R.D., Rojas, K.W., Ahuja, L.R., Ma, L. and Malone, R.W. (2004). The pesticide module of the Root Zone Water Quality Model (RZWQM): testing and sensitivity analysis of selected algorithms for pesticide fate and surface runoff. Pest management Science 60, 240-252.

NQ Dry Tropics (2009). Reef Rescue ABCD framework for sugar producers in the Burdekin 2009. North Queensland Dry Tropics Regional Management Body, http://www.nqdrytropics.com.au/.

Packett, R., Dougall, C., Rohde, K. and Noble, R. (2009). Agricultural lands are hot-spots for annual runoff polluting the southern Great Barrier Reef lagoon. Marine Pollution Bulletin 58, 976-986.

Rattray D.J., Freebairn D.M., McClymont, D., Silburn D.M., Owens J. and Robinson J.B. (2004) HOWLEAKY? - the journey to demystifying simple technology. Conserving Soil and Water for Society: Sharing Solutions ISCO 2004, the 13th International Soil Conservation Organisation Conference. Brisbane, July 2004.

Robinson, J.B., Silburn, D.M., Rattray, D., Freebairn, D.M., Biggs, A.J.W., McClymont, D. and Christodoulou, N. (2010). Modelling shows that the high rates of deep drainage in parts of the Goondoola Basin in semi-arid Queensland can be reduced with changes to the farming systems. Australian Journal of Soil Research 48, 58-68.

Shaw, M., Furnas, M., Fabricius, K., Haynes, D., Carter, S., Eaglesham, G. and Mueller, J. F. (2009). Monitoring pesticides on the Great Barrier Reef. Marine Pollution Bulletin 60, 113-122.

Silburn, D.M. (2003). Characterising pesticide runoff from soil on cotton farms using a rainfall simulator. PhD thesis, University of Sydney, Sydney.

Strahan, R. and Hoffman, A. (2009). Estimating the economic implications for broad acre cropping farms in the Fitzroy Basin catchments of adoption of best management practices. Department of Employment, Economic Development and Innovation, The State of Queensland.

Walker, A., Helwig, A and Jacobsen, O.S. (1997) Temperature and pesticide degradation. In Soil persistence models and EU registration, FOCUS documentation, http://viso.ei.jrc.it/focus/, Chapter $1,9-20$. 